\title{
The lung in closeview: a corrosion casting study on the vascu- lar system of human foetal trachea
}

\author{
P. Strek*, M. Nowogrodzka-Zagórska**, J.A. Litwin†, A.J. Miodoński**
}

\begin{abstract}
The lung in closeview: a corrosion casting study on the vascular system of human foetal trachea. P. Strek, M. Nowogrodzka-Zagórska, J.A. Litwin, A.J. Miodoński. CERS Journals Ltd 1994.

ABSTRACT: The aim of this study was to examine the tracheal vasculature in 5 month human foetuses, and to determine whether it differs from that previously described by other authors for adult human trachea.

The vascular bed was visualized using the technique of corrosion casting and examined by scanning electron microscopy.

The arrangement of larger vessels: longitudinal tracheo-oesophageal arteries and veins, as well as their segmental branches running circumferentially in the intercartilaginous spaces, was similar to that observed in the trachea of adults. However, no blood sinuses reported to occur in the submucous venular plexus of the human trachea could be found in the foetuses.

It is postulated that the possible functions of such sinuses acting as the capacitance system are related to the functional respiratory tract; hence, this vascular specialization is not yet developed in the foetus.
\end{abstract}

Eur Respir J., 1994, 7, 1669-1672.

\author{
*Dept of Anatomy, **Laboratory of Scan- \\ ning Electron Microscopy, Dept of Oto- \\ rhinolaryngology and $†$ Dept of Histology, \\ Jagiellonian University School of Medicine, \\ Cracow, Poland. \\ Correspondence: A.J. Miodoński \\ Laboratory of Scanning Electron Microscopy \\ Dept of Otorhinolaryngology \\ Jagiellonian University School of Medicine \\ Kopernika 23a \\ 31-501 Kraków \\ Poland
}

Keywords: Blood sinuses, corrosion casting, foetus, trachea, vasculature

Received: August 231993

Accepted after revision January 191994
The vascular system of the tracheobronchial tree performs a variety of functions: apart from those common to most vascular beds, such as nourishment of tissues, removal of waste materials or supply of migratory cells and mediators, it is also involved in the specific functions of the airways related to the conditioning of inspired and expired air [1-4]. In the case of human trachea, its microcirculation provides a clue to the intubation-induced ischaemia and subsequent mucosal damage [5-7]. In man, the tracheal vasculature has been investigated mainly with the use of classical histological techniques, dye injection methods and intravital microscopy [8-10]. We employed the corrosion casting technique in combination with scanning electron microscopy (SEM) [11], which offered a higher level of visualization of the vascular system. With its substantially improved resolution and quasi-3-dimensional images, this technique is especially suitable for verification of earlier, light microscopic studies.

This study was aimed at the examination of the human tracheal vasculature in the foetal period, when the airways are not functional. It seemed particularly interesting to determine whether the features of the vascular system regarded as air-conditioning specializations were already developed.

\section{Materials and methods}

Five human foetuses, aged 18-21 gestational weeks, with crown-rump length ranging 170-209 mm, were obtained after spontaneous abortions from the Obstetric Clinic of the Jagiellonian University School of Medicine in Cracow. The abortions were due to maternal disorders, and no developmental malformations or vascular anomalies were found in the foetuses upon macroscopic inspection.

After abortion, the thorax of each foetus was opened to expose the heart and large vessels. The heart apex was cut off and a cannula was inserted via the left ventricle to aorta and fixed by ligation at the level of the ascending part. The vascular system of the foetus was subsequently perfused manually using a sequence of solutions, with the outflow occurring via the umbilical vessels and additionally incised posterior tibial veins.

The perfusion started with $800 \mathrm{ml}$ of prewarmed $\left(37^{\circ} \mathrm{C}\right)$ heparinized saline $\left(12.5 \mathrm{IU} \cdot \mathrm{ml}^{-1}\right)$ containing $3 \%$ dextran, MW 70,000, and $0.025 \%$ lidocaine. Perfusion fixation was then carried out with $200 \mathrm{ml}$ of $0.08 \%$ glutaraldehyde in $0.15 \mathrm{M}$ cacodylate buffer, $\mathrm{pH} 7.4$, at $37^{\circ} \mathrm{C}$. Finally, $60 \mathrm{ml}$ of a mixture consisting of $8 \mathrm{ml}$ Mercox CL-2B (Vilene Comp., Tokyo, Japan) and $2 \mathrm{ml}$ methyl methacrylate (Fluka) containing $0.2 \mathrm{~g} \mathrm{~N}, \mathrm{~N}-$ dimethylaniline (MA) initiator was injected. Following the injection, the foetuses were kept overnight in water at $60^{\circ} \mathrm{C}$, in order to accelerate and complete resin polymerization.

After polymerization of the resin, the trachea was removed and washed in distilled water. The specimens were then macerated in $8-10 \% \mathrm{NaOH}$ at $38^{\circ} \mathrm{C}$. The vascular casts obtained were carefully and thoroughly cleaned in hot tap water, followed by several rinses in 
distilled water. The final cleaning was accomplished by immersing the casts for $3-5 \mathrm{~min}$ in $2 \%$ formic acid. The casts were again carefully washed in distilled water, freeze-dried and mounted on stubs using colloidal silver and "conductive bridges" [12].

After coating with gold, the casts were examined in a Jeol JSM 35-CF scanning electron microscope at 20$25 \mathrm{kV}$.

\section{Results}

The corrosion cast of foetal trachea reveals its dense and complex vascular system (fig. 1). This system has a distinct segmental arrangement, corresponding to the arrangement of tracheal cartilages. The blood supply and drainage for the entire trachea is provided by two laterally located longitudinal bundles of large vessels, containing both arteries and veins, as revealed in the SEM image by their characteristic nuclear imprints (fig. 2). They regularly send off segmental vessels, i.e. horizontal branches located at the levels of intercartilaginous spaces, and thus running a circumferential course (figs 1 and 2). The arteries supplying two adjacent segments are occasionally interconnected by vertically or obliquely running interconnections (fig. 3).

The segmental arteries first give off small branches to the superficial, perichondrial vascular bed made of fine capillaries, 6-10 $\mu \mathrm{m}$ in diameter (fig. 2), and then further ramifications which pierce the tracheal wall to reach the mucosal lining and to supply its microcirculation.

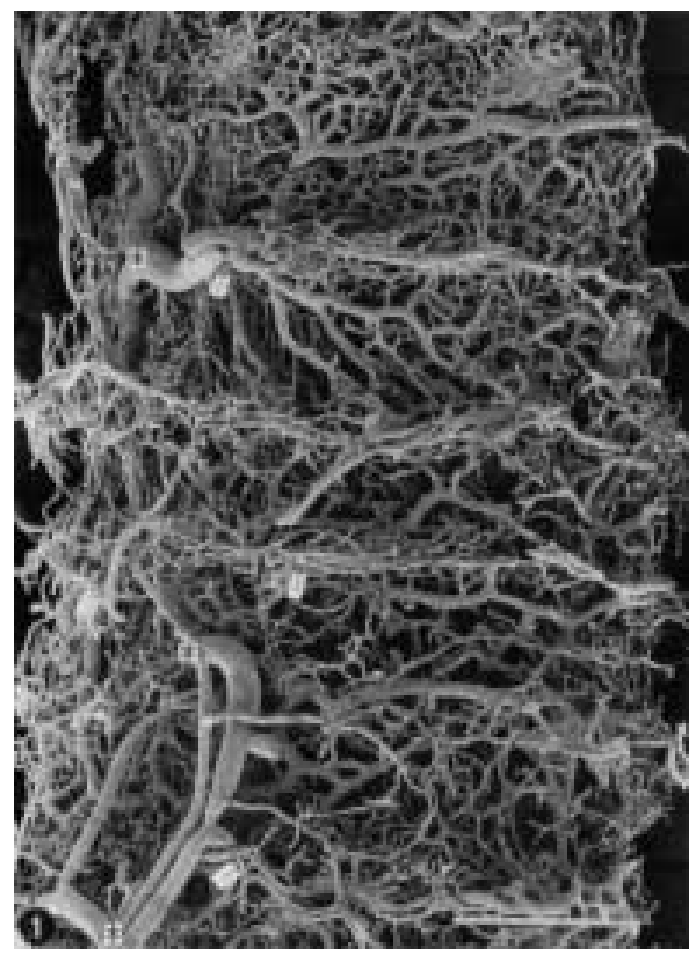

Fig. 1. - General view of the vascular cast of the human foetal trachea, right lateral aspect. Longitudinal vessels (asterisks) send off segmental branches located in the intercartilaginous spaces (arrows). (Scale bar=1,000 $\mu \mathrm{m})$.

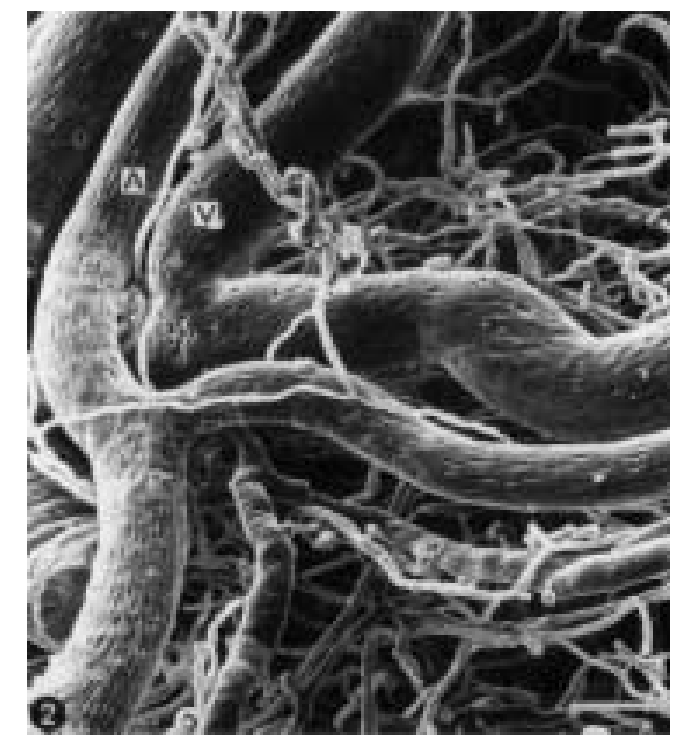

Fig. 2. - A site of branching of the longitudinal vessels into the segmental ones. Artery (A) and vein (V) can be distinguished according to the appearance of the nuclear imprints: fusiform in the artery, more roundish in the vein. Fine capillaries belong to the perichondrial network. (Scale bar=100 $\mu \mathrm{m})$.

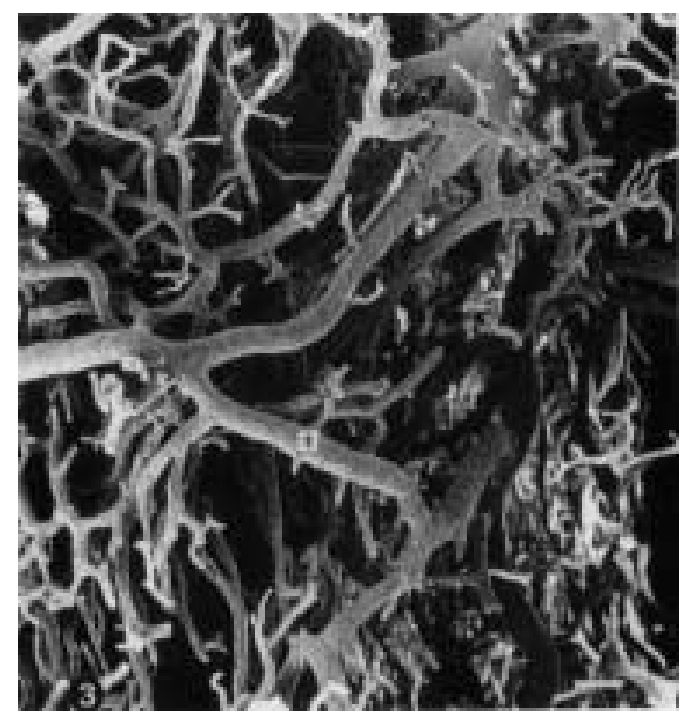

Fig. 3. - An anastomosis (asterisk) interconnecting two segmental arteries. (Scale bar $=100 \mu \mathrm{m})$.

This microcirculation is basically composed of two layers: 1) a subepithelial capillary network; and 2) a submucous plexus, which includes mainly veins.

The subepithelial vascular layer is built of capillaries, 12-15 $\mu \mathrm{m}$ in diameter, which form a network with irregular meshes (fig. 4). In the mucosa of the posterior part of trachea (pars membranacea), this network alters its arrangement: the capillaries are more densely packed and mostly run along the long axis of the trachea, so that the resulting vascular array is characterized by elongated meshes (fig. 5).

The submucous plexus is mostly composed of venous vessels. Their diameter is about $30-50 \mu \mathrm{m}$ and they are interconnected by numerous anastomoses, thus forming 


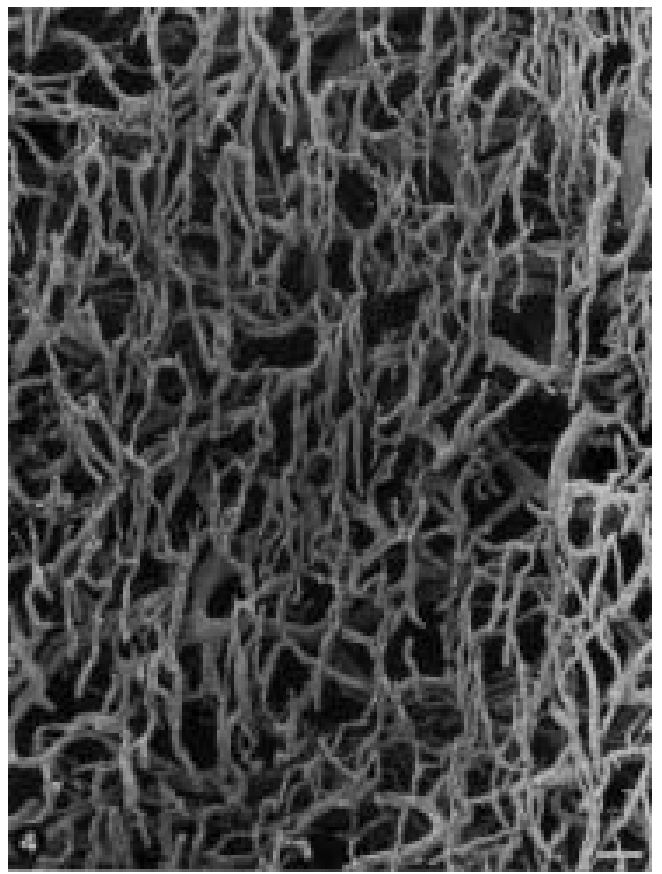

Fig. 4. - Subepithelial capillary network in the cartilaginous part of the trachea. Profiles of the deeper, submucosal venous plexus can be partially seen underneath. (Scale bar $=100 \mu \mathrm{m}$ ).

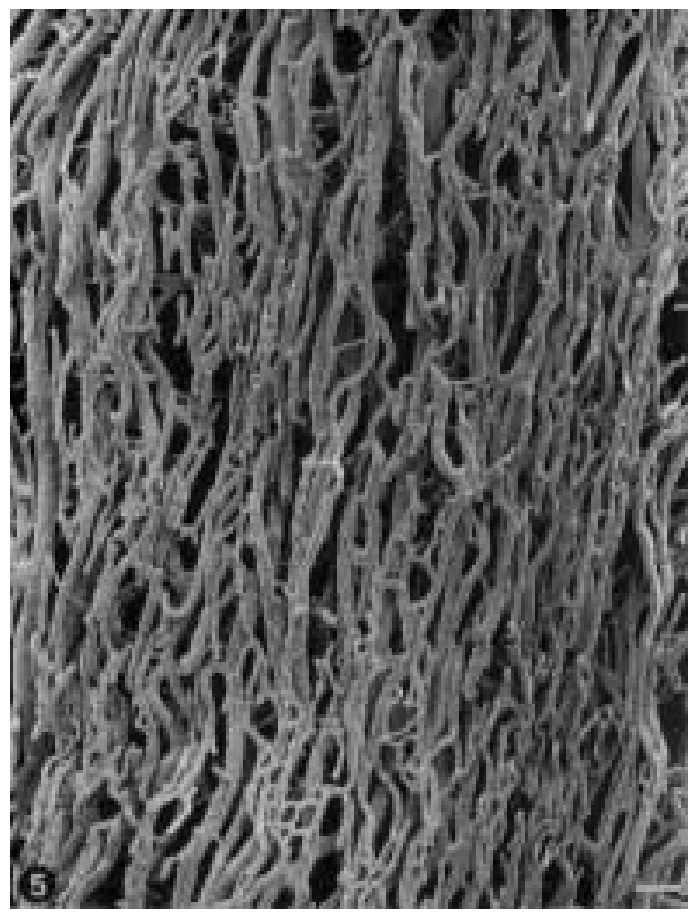

Fig. 5. - Subepithelial capillary network in the membranaceous part of the trachea. The capillaries show mostly a longitudinal orientation. (Scale bar=100 $\mu \mathrm{m}$ ).

an irregular network with large meshes. Generally, these vessels do not show a sinusoidal character (i.e. large diameter and uneven outlines), although in some places more densely packed interconnections lead to the formation of irregular vascular profiles (fig. 6), which might eventually develop into sinuses. The veins of the submucous plexus are drained by segmental veins.

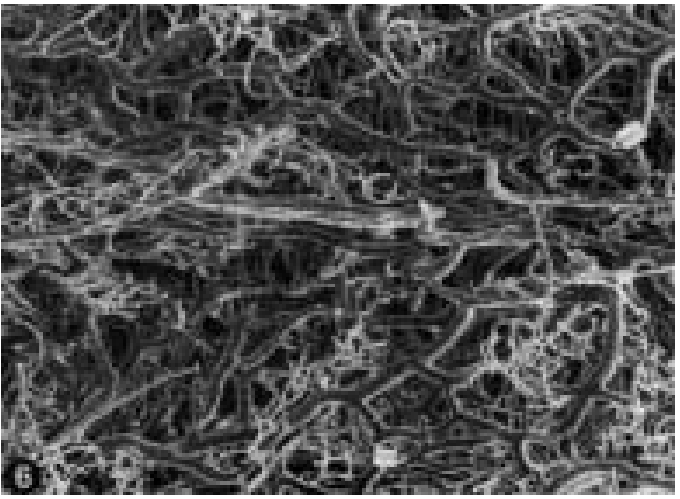

Fig. 6. - The submucous venous plexus in a form of network with large meshes. In some sites the venules converge into sinusoidal profiles (arrows). (Scale bar $=100 \mu \mathrm{m})$.

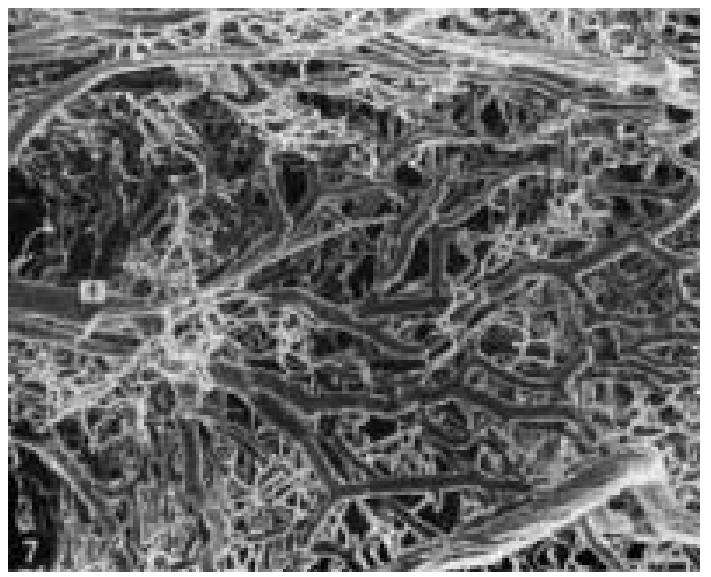

Fig. 7. - A segmental vein (asterisk) draining the submucous plexus covering a large area of two adjacent tracheal segments. (Scale bar=100 $\mu \mathrm{m})$.

Sometimes a single segmental vein can collect blood from a large area, encompassing two entire adjacent segments (fig. 7). Arteriovenous anastomoses have not been observed.

\section{Discussion}

The postmortem preparation of the vascular casts is often hampered by an incomplete filling of the capillary bed. This can also be seen in our material, in the form of blindly ending vascular branches (e.g. fig. 3). Such artefacts are, however, local and the vast majority of the capillaries remains patent, leading to the visualization of the entire vasculature including veins.

Results of this study, the first to visualize the human foetal tracheal vasculature by corrosion casting and scanning microscopy, clearly show that the general arrangement of the blood vessels is similar to that seen in adult humans and some other mammals. The tracheal blood vessels were investigated with the use of that technique in the dog [3], sheep [1], guinea-pig [13], and rat [14]. In all these species, as well as in some others investigated by light microscopy, such as rabbit or cat, the blood is supplied to and drained from the 
trachea by lateral longitudinal vessels, called longitudinal tracheo-oesophageal vessels by NoRDIN et al. [15], which send off regularly circumferential (segmental) branches located in the intercartilaginous spaces. As revealed by the appearance of endothelial nuclear imprints [16], longitudinal and segmental vascular bundles are composed both of arteries and veins running together.

Interspecies differences concern mainly the microcirculation of the tracheal mucosa. The regional differentiation of the subepithelial capillary network, described in this study, was also reported in rat trachea [14], where the authors observed irregular meshes in the pars fibrocartilaginea and "rectangular" (longitudinal) ones in the pars membranacea. In previous studies on adult human trachea $[9,10]$, the authors did not comment on the arrangement of subepithelial capillaries, but the published micrographs revealed their random orientation. Irregular distribution of tracheal subepithelial capillaries was also demonstrated in sheep and dog, although a longitudinal arrangement seemed characteristic for the bronchial mucosa of those species $[1,3]$. The differentiation of the capillary pattern observed in this study could represent some regional specialization of the foetal mucosa, but it can also result from a fixationinduced constriction of the smooth muscle present in that part of tracheal wall.

One of the most interesting features of the tracheal microvasculature is the presence of venous sinuses in the submucosal plexus. An extensive system of sinuses has been demonstrated in sheep and rabbit, it is less developed in man and guinea-pig, and very scanty in cat and dog $[1-3,13]$. In the adult human trachea, blood-filled sinuses up to $100 \mu \mathrm{m}$ in diameter were described $[2,17,18]$. We could not find such sinuses in any of the tracheas obtained from 5 month foetuses that were examined. However, in some areas of the submucosal venous plexus the converging vessels produced irregular vascular spaces that could be regarded as "primordial sinuses".

There are at least a few possible functions of blood sinuses acting as a capacitance system in the tracheal wall [4]. They might provide a blood reservoir and participate in the conditioning of the inspired air, although in nose-breathers the nasal vasculature, with its extensive sinusoidal system and arteriovenous anastomoses, would much more efficiently play that role. They could act as heat reservoirs, buffering the changes of tracheal wall temperature in the course of the respiratory cycle and protecting functions sensitive to cooling and/or drying, such as tracheal secretion or muscle tone. They could also serve as a mechanical cushion. Strikingly, all these putative activities are related to the functional respiratory tract, thus they are not required in the foetal period. It seems, therefore, logical that the sinus system is not yet developed in the foetus.

\section{References}

1. Hill P, Goulding D, Webber SE, Widdicombe JG. Blood sinuses in the submucosa of large airways of the sheep. J Anat 1989; 162: 235-247.

2. Hughes T. Microcirculation of the tracheobronchial tree. Nature 1965; 206: 425-426.

3. Laitinen A, Laitinen LA, Moss R, Widdicombe JG. Organization and structure of the tracheal and bronchial blood vessels in the dog. J Anat 1989; 165: 133-140.

4. Widdicombe JG. Comparison between the vascular beds of upper and lower airways. Eur Respir J 1990; 3 (Suppl. 12): $564 \mathrm{~s}-571 \mathrm{~s}$.

5. Cooper ID, Grillo HC. The evolution of tracheal injury due to ventilatory assistance through cuffed tubes: a pathologic study. Ann Surg 1969; 169: 334-339.

6. Donnelly WH. Histopathology of endotracheal intubation. An autopsy study of 99 cases. Arch Pathol 1969; 88: 511-516.

7. Stenqvist O, Baage U. Cuff pressure and microvascular occlusion in the tracheal mucosa. Acta Otolaryngol 1979; 88: 451-454.

8. McDonald DM. The ultrastructure and permeability of tracheobronchial blood vessels in health and disease. Eur Respir J 1990; 3 (Suppl. 12): 572s-585s.

9. Salassa JR, Pearson BW, Payne WS. Gross and microscopical blood supply of the trachea. Ann Thorac Surg 1977; 24: 100-107.

10. Stenqvist $\mathrm{O}$, Baage U, Nilsson K. The tracheal mucosa microvasculature and microcirculation: intravital microscopic observations in rabbits and a histologic study in man. Acta Otolaryngol 1979; 87: 123-128.

11. Lametschwandtner A, Lametschwandtner U, Weiger T. Scanning electron microscopy of vascular corrosion casts - technique and applications: updated review. Scanning Microsc 1990; 4: 889-941.

12. Lametschwandtner A, Miodoński A, Simonsberger P. On the prevention of specimen charging in scanning electron microscopy of vascular corrosion casts by attaching conductive bridges. Mikroskopie 1980; 36: 270-273.

13. Miodoński A, Kuś J, Tyrankiewicz R. Scanning electron microscopical study of tracheal vascularization in guinea-pig. Arch Otolaryngol 1980; 106: 31-37.

14. Lametschwandtner A, Staindl O, LametschwandtnerAlbrecht U, Grunt T. Die Vaskularisation der zervikalen Trachea und ihre klinische Relevanz. Eine rasterelekronenmikroskopische Untersuchung an Korrosionpräparaten. Hals-Nasen-Ohrenheilk 1983; 31: 387-394.

15. Nordin U, Bergstrom B, Jansson B, Lindholm C-E. Surface structure and vascular anatomy of the tracheal wall under normal conditions and after intubation. Acta Otolaryngol 1977; (Suppl. 345): 35-57.

16. Miodoński A, Hodde KC, Bakker C. Elekronenmikroskopie von Plastik-Korrosions-Präparaten: Morphologische Unterschiede zwischen Arterien und Venen. BEDO (Münster) 1976; 9: 435-442.

17. Murata $\mathrm{K}$, Itoh $\mathrm{H}$, Todo $\mathrm{G}$, et al. Bronchial venous plexus and its communication with pulmonary circulation. Invest Radiol 1986; 21: 24-30.

18. Corfield DR, Hanafi Z, Webber SE, Widdicombe JG. Structural studies of the tracheal vasculature in several species including man. Eur Respir J 1990; 3 (Suppl. 12): $675 \mathrm{~s}$. 